\title{
8. A POLÍTICA DE ASSISTÊNCIA SOCIAL NA PANDEMIA: há uma crise sanitária no caminho da crise do capital*
}

Mossicleia Mendes da Silva

\section{Introdução}

A identificação de uma nova variação do vírus Corona, ainda em fins de 2019 na China, não causou, de imediato, uma preocupação global e a interpretação corrente levava a crer que se trataria de um fenômeno muito similar ao SARS, que já havia provocado um surto em 2003 e que ficaria restrita aquele país (HARVEY, 2020). No entanto, aquele episódio ocorrido em Whuan não seria de modo nenhum um fenômeno isolado. A propagação do novo Coronavírus e sua doença a Covid -19 se espalhou para os cinco continentes em intensa velocidade, com potencial de infeção e propagação de altíssimo alcance, sendo declarada Situação de Emergência em Saúde Pública de Importância Internacional pela Organização Mundial da Saúde em 30 de janeiro de 2020.

Ao contrário do que se especulou, inicialmente, o mundo passou a enfrentar uma das maiores crises sanitárias vivenciadas pela humanidade, com grande impacto sobre as condições de vida de populações mundo afora, colapso de sistemas de saúde, abalos sobre a Bolsa de Valores, alvoroço político e medidas de distanciamento, isolamento social e até mesmo quarentena absoluta, em alguns países.

A paralisação da produção e circulação de mercadorias e de pessoas provocou abalo profundo no circuito de valorização do capital e não tardou para que o "vírus" fosse transformado no grande "vilão" ou uma "causa aleatória" externa ao capitalismo que seria responsável pela deflagração da crise econômica e a recessão global que o mundo adentrou. No entanto, desde a perspectiva da crítica da 
economia política, compreendemos que a crise em curso é mais uma manifestação da crise estrutural do modo de produção capitalista que, em função da crise sanitária, teve suas condições e consequências potencialmente aprofundadas. Neste sentido, concordamos com Botelho (2020) ao afirmar que a crise em tela não é resultado de

[...] interferência externa, muito menos é o mecanismo de "limpeza de terreno" de sempre", mas trata-se de "problemas estruturais em processo há quatro décadas que têm empilhado soluções mundiais fracassadas. Somente o positivismo sedimentado como forma corriqueira do pensamento pode estabelecer um vírus como causa de uma crise econômica" (BOTELHO, 2020, n/p).

No Brasil, a confirmação do primeiro caso se deu em fevereiro e rapidamente a propagação da doença atingiu níveis importantes, colocando as autoridades sanitárias, pesquisadores e determinados setores da sociedade em alerta, embora o governo Federal assumisse uma postura claramente negacionista em relação aos efeitos letais do novo coronavírus e da necessidade de medidas rápidas de contingenciamento.

Em 20 de março de 2020 o Congresso Nacional aprovou, por unanimidade, "estado de calamidade pública". Neste contexto, foram especificados os serviços essenciais, definidos como "aqueles indispensáveis ao atendimento das necessidades inadiáveis da comunidade, assim considerados aqueles que, se não atendidos, colocam em perigo a sobrevivência, a saúde ou a segurança da população", nos quais está inserida a "assistência social e atendimento à população em estado de vulnerabilidade" (BRASIL, 2020).

A decretação presidencial quanto à inserção da assistência social no rol dos serviços essenciais se seguiu de uma série de normatizações entre Portarias, Notas Técnicas e Orientações do Ministério da Cidadania para organizar e dá suporte aos Estados e municípios na condução de benefícios e rede socioassistenciais para fazer frente as demandas em função da pandeia. Também foram significativas Notas Públicas e Recomendações de Instâncias Colegiadas de pactuação como o Colegiado Nacional de Gestores Municipais de Assistência So- 
cial - CONGEMAS, O Fórum Nacional de Secretários/as de Estado da Assistência Social - Fonseas, Fóruns de Trabalhadores do SUAS (nacional e estaduais), bem como de Conselhos Profissionais, cuja classe compõem as equipes de referências dos serviços de assistência social.

Conforme indicamos a crise econômica atual não é resultante exclusiva da pandemia, mas expressão da própria crise estrutural do capital e já colocava um quadro de radicalização neoliberal, em processo no Brasil desde 2016, que vem provocando o desmonte das políticas sociais e a intensificação das expropriações de direitos. O objetivo central do presente artigo é, portanto, problematizar as condições concretas pelas quais o Sistema Único de Assistência Social (SUAS) vem incidindo no contexto de crise sanitária e as demandas da população usuária nesse contexto, sendo uma política social de institucionalidade recente e fragilizada face aos atuais ataques, desfinanciamento e desmonte.

\section{Crise do capital, pandemia e governo Bolsonaro}

Entre o medo da doença e o alardeado risco econômico em função das medidas de isolamento social horizontal, assistiu-se o acirramento da irresponsabilidade do governo Federal frente as demandas da sociedade - sobretudo da classe trabalhadora - ao assumir discurso negacionista e mostrar-se frontalmente contrário à paralisação das atividades econômicas, alimentando debates acirrados contrários aos especialistas em epidemiologia, infectologia e saúde pública, sobre a necessidade de medidas importantes para contenção do avanço da doença. ${ }^{1} \mathrm{O}$ que evidenciou, mais do que nunca, o caráter reacionário e fascista que assenta as bases desse governo e sua intricada relação com o grande capital, evidenciando, conforme atesta

\footnotetext{
${ }^{1}$ Foram muitos os impasses e conflitos dentro do próprio governo no tocante às medidas de enfrentamento à Covid-19. Exemplo exímio foram as discórdias e discrepâncias entre o discurso e medidas propostas pelo Ministério da Saúde e as falas e atitudes do presidente da república. Conflito de tamanha alçada que culminou na demissão de dois Ministros da Saúde (Luíz Henrique Mandetta e Nelson Reich). Em 19 de junho de 2020 o País tem mais de 1 mi Ihão de casos confirmados, mais de 40 mil mortos e o Ministério da Saúde segue sem Ministro oficial, estando sob comando de um General do Exército.
} 
Carnut (2020), a preocupação do governo Bolsonaro diante da crise da pandemia: priorizar o lucro e não vidas. Sob essa postura, calcada no obscurantismo, o governo Federal se mostrou extremamente negligente e ineficiente no enfrentamento à pandemia, passando longe do que se esperava de um governo minimamente sério. Além de não conseguir elaborar e implementar um plano nacional, liderando e articulando as ações dos estados para essa empreitada, o governo Federal se emaranhou entre troca de ministros, escândalos políticos e inoperância para reorganizar o sistema de saúde e medidas de proteção social aos brasileiros. Rodrigues e Stampa (2020) chamam atenção para o fato de que o governo Bolsonaro - em forte consonância com sua postura subserviente aos EUA - não só convergiu com os argumentos chulos de Donald Trump, como revelou "indícios adicionais do alinhamento automático do Brasil à tomada de decisões estratégicas nos EUA" (p.89).

Não constitui novidade histórica que o Estado capitalista ainda mais nos moldes do capitalismo dependente - faça clara opção pelos interesses do capital em detrimento das necessidades sociais, mas assumir a feição descarada de colocar toda população em risco iminente de morte para retomar as atividades econômicas requer as bases de um governo de bases fascistas e terraplanistas.

O que nos ajuda a entender como as situações complexas desencadeadas pela pandemia passam a servir de cortina de fumaça sobre as causas centrais do colapso econômico mundial. As repercussões das paralisações de produção em diversos ramos, o fechamento do comércio, paralisação do turismo e de importantes setores de ramos dos serviços por conta da Covid 19, que têm contribuído para aprofundamento da recessão econômica, são apontados não como um componente detonador da crise latente que assombrava o capitalismo mundial, mas como sua causa precípua.

Do ponto de vista da crítica marxista do capitalismo, sabe-se que a crise capitalista deflagrada em 2008 mantinha seus reveses, com alguns deslocamentos espaciais e momentâneos, mantendo a economia global sempre na berlinda imposta pelos recorrentes óbices à realização do valor e a garantia de aumento das taxas de lucro e acumulação. Segundo Chesnais (2020), no final de 2019, mesmo após 
dozes anos do início daquela crise, não tinha acontecido uma verdadeira retomada da acumulação nos países avançados da OCDE, ao mesmo tempo em que o ritmo de crescimento da China havia caído.

Na véspera da pandemia, as perspectivas de crescimento da economia mundial para 2020, publicadas pela OCDE, eram de 2,9\%. No início de 2020, a produção industrial dos EUA havia caído, pelos cálculos do Fed, em 0,4\% em comparação com o nível do mesmo mês do ano anterior. [2] Na Alemanha, a segunda maior economia da OCDE, a produção industrial caiu $1,7 \%$, em outubro de 2019. Dependente das exportações, a indústria alemã sofreu os efeitos da desaceleração endógena do crescimento chinês, do fraco desempenho de países vizinhos da Europa e do impacto do Brexit nos projetos de investimento da UE (CHESNAIS, 2020, n/p).

Assim, a explosão da recessão global, que se anuncia nos "circuitbreaker" das mais importantes Praças das Bolsa de Valores do mundo e nas anunciadas quedas dos PIBs das principais potências capitalistas, tem na pandemia um efeito catalisador e explosivo, mas não é seu núcleo ou causa central. A crise que ora eclode é expressão das contradições próprias do capitalismo, que mesmo exaurindo recursos naturais e humanos, espoliando e expropriando direitos dos trabalhadores e levando ao limite o nível de barbarização das relações sociais, não consegue suplantar sua propensão a crises. Isto por que, o planeta, seus recursos e a humanidade não podem suportar, sem abalos, o modelo da economia capitalista que somente se sustenta como "uma espiral de expansão e crescimento sem fim" (HARVEY, 2019, s/p). Propensão essa cada vez mais aberta e adensada em função da expansão do capitalismo financeiro e sua fração parasitária que opera sem limites expondo economias nacionais, Estados e populações às suas flutuações e incapacidade de fazer dinheiro sem passar pelo processo produtivo de trabalho (IAMAMOTO, 2008).

No Brasil, a crise capitalista intensifica a ofensiva contra a classe trabalhadora, num contexto de escalada do conservadorismo e aprofundamento do ajuste fiscal, com a aprovação da Emenda Constitucional 95 (2016), Contrarreformas como a Trabalhista (2017) e 
Previdenciária (2019) que, acopladas a outra série de medidas reacionárias, acentuaram os níveis de pobreza, desemprego e precarização do trabalho.

As políticas sociais vêm padecendo do desfinanciamento, intensificado com a EC /95 e os efeitos de contingências diversas como as implicações da Desvinculação de Receitas da União (DRU), por exemplo, sobre as receitas da Seguridade Social, que há tempos surrupiam recursos exclusivos dessas políticas, intensificando a canalização do Fundo Público para as demandas do capital, sobretudo sua fração financeirizada através do pagamento de juros e amortizações da Dívida Pública (BENHRING, 2017). Ao mesmo tempo, contrarreformas como a Previdenciária abrem novos nichos de investimento e acumulação para o capital financeiro (DILIGENTE e ARAÚJO, 2019) e as expropriações de direitos trabalhistas, viabilizados pela intensificação da flexibilização das regulamentações atinentes ao trabalho, consolidadas sob a Lei da Terceirização e, sobretudo, na contrarreforma trabalhista concretizam a pilhagem do trabalho e jogam os trabalhadores no âmbito da exposição máxima e sujeição quase que absoluta ao trabalho mais precarizado, degradante e espoliativo (ANTUNES, 2018).

No que se refere a explicação da crise, é hegemônica também por aqui a retórica da culpabilização da pandemia pela crise econômica, mas apesar da política ultraliberal aplicada pelo Ministro Paulo Guedes, a economia nacional apresentava desempenho pífio, com desvalorização do real, tímida recuperação do PIB, aumento do desemprego e da pobreza antes da pandemia. Peixoto (et al, 2020) indicam que a taxa de crescimento de 1,1 \% em 2019 foi a menor em 3 anos sendo "a mais débil recuperação de recessão que se tem registro no Brasil" (p.37). Já o PIB per capta do ano passado ficou abaixo do de 2010

O processo de desindustrialização deu continuidade a recessão industrial de 2019 , com menos $1,1 \%$, ao passo que o fluxo de novos investimentos, que representava $20 \%$ do PIB antes da recessão, chegou em 2019 a 15,4 \% (CEM FLORES, 2020). Os dados do mercado de trabalho também são ilustrativos da estagnação econômica. 
Já vimos os 12,6 milhões de trabalhadoras/es desempregados no ano passado (taxa de desemprego de $11,9 \%$ ). A esses, é preciso acrescentar outros 7,0 milhões em tempo parcial involuntário e mais 8,0 milhões que nem se dão ao trabalho de procurar emprego, pela certeza de não encontrar (que o IBGE chama de "força de trabalho potencial"), somando os 27,6 milhões de subocupados ( $24,2 \%$ do total). $E$ isso sem contar os 4,7 milhões de desalentados (número que só cresce nos últimos anos) (CEM FLORES, 2020, n/p).

É nesse solo histórico que precisamos situar a crise pandêmica do novo Coronavírus e a política de assistência social como serviço essencial: um país objeto de duras medidas de austeridade fiscal, assentadas no desfinanciamento e desmonte das políticas sociais e que ainda assim não vinha tendo sucesso na retomada do crescimento econômico, mas com aprofundamento da desigualdade social, da pobreza e da precarização do trabalho.

Nos últimos anos a política de assistência social vinha ganhando centralidade no âmbito da proteção social brasileira, assumindo funcionalidade específica para dar conta de demandas da reprodução da classe trabalhadora, sobretudo sua fração mais empobrecida ou, para usar termos do Marx, aquele contingente que compõe a superpopulação relativa estagnada. Neste sentido, vale recuperar brevemente os processos que transformaram as feições e o modus operandi da política de assistência social brasileira.

\section{A Política de Assistência Social no Brasil: notas sobre sua trajetória recente}

A aprovação da Política Nacional de Assistência Social (PNAS), em 2004, foi uma baliza importante para regulamentação de política de assistência social. A nova PNAS trouxe parâmetros importantes para a implementação do Sistema Único de Assistência Social, aprovado em 2005 através da Norma Operacional Básica do SUAS (NOBSUAS) demarcando uma mudança substancial, ao menos em termos de normatização das questões definidas na LOAS e às próprias demandas de setores ligados à assistência social que há tempos pleitea- 
vam por uma direção normativa da política. A partir de então seguiuse uma espécie de "choque de gestão" (BEHRING, 2009), que consolidou um importante arcabouço político-normativo e institucional que sedimentaram bases para implementação e expansão do SUAS em todo território nacional.

Na década que compreende o período de 2004 a 2014, durante os governos petistas, a assistência social brasileira passou por um processo de expansão, marcado por contradições entre a implantação e consolidação do Sistema Único de Assistência Social (SUAS) e a centralidade da via focalista e seletiva dos programas de transferência de renda. Pela via de um processo que designamos de modernização conservadora, a direção sociopolítica neste campo de proteção social engendrou uma estratégia de gestão da pobreza - para dar conta da fração mais empobrecida da classe trabalhadora e conter as expressões mais disruptivas da questão social -, mas também consolidou um movimento importante de institucionalização, normatização e regulamentação dos programas, projetos, benefícios, serviços e projetos sobre um sistema único descentralizado e participativo de fundamental importância, no âmbito de uma política social marcada pelo histórico descaso, casuísmo, fragmentação e confusionismo entre o público e o privado, com forte presença do caldo cultural conservador do assistencialismo, paternalismo e benemerência.

Neste contexto, a política de assistência social alcançou um importante patamar de consolidação e o SUAS se capilarizou nos municípios brasileiros, estando presente - com equipamentos sociais como os Centros de Referência de Assistência Social (CRASs) em mais de $95 \%$ deles. Ao revés da histórica dispersão dos programas assistenciais, que conformaram por longo tempo as ações deste campo, o SUAS viabilizou um formato de gestão com comando único e descentralização político-administrativa, com a constituição dos Fundos $\mathrm{Na-}$ cionais, estaduais e municipais de assistência social que permitiu, pela via do cofinanciamento federal expandir a rede de serviços.

Alçou outro lugar no governo federal e a participação orçamentária no campo da seguridade social cresceu relativamente muito mais do que as outras políticas como Saúde e Previdência. O que aponta para contradições que estão no cerne da expansão da política 
de assistência social nesse contexto, tal como indicado por Mota (2008): "as políticas de seguridade social brasileira longe de formarem um amplo e articulado mecanismo de proteção, adquiriram a perversa posição de conformarem uma unidade contraditória [...]" (MOTA, 2008, p. 133).

O crescimento do volume de recursos na política de assistência social esteve em forte medida assentado na expansão dos programas de transferência de renda, condição essa que impôs uma série de tensionamentos por consolidar uma modalidade de política social focalista e seletiva, embora indispensável para reprodução material da força de trabalho mais precarizada ou aqueles que comporiam o Marx denominou de lupem proletariado.

Em suma, o modo pelo qual o SUAS é implementado é carregado de uma série de contrassensos e até mesmo inconsistências que dificultam substancialmente a consolidação do padrão de proteção social assegurado na Constituição Federal e a solidificação de uma rede de serviços socioassistenciais de fato pública e de qualidade. Infelizmente, esse processo de regulamentação da política e implementação do SUAS, apesar do valor simbólico e material que comporta para assistência social, se processa em um contexto onde a crise do capital bole sua ofensiva conservadora abalizam novos determinantes ao processo que convergem na direção dos próprios interesses dominantes, na medida em que se realizam mediante forte influência de uma segunda geração de ajustes neoliberais (SILVA, 2018).

A partir do governo Temer, é possível observar retrocessos na política de assistência social, com a criação o Programa Criança Feliz, cuja embaixadora era Marcela Temer, esposa do presidente reavivando o fantasma do primeiro-damismo no campo da assistência social. Ademais, os investimentos públicos na política de assistência começam a minguar, com fortes cortes orçamentários a partir de 2017 e que se aprofunda em 2018 face à intensificação do ajuste fiscal e da ofensiva ultraconservadora do capital em direção às políticas sociais.

Com a chegada de um governo de extrema direita ao governo federal, o processo de desmonte da já frágil estrutura do SUAS - com a continuidade do corte de recursos - é acompanhada por uma ofensiva político-ideológica contra a institucionalidade democrática cons- 
truída na área nos últimos anos, do que é elucidativo a desestruturação dos Conselhos de Direitos e a não convocação da Conferência Nacional de Assistência Social, que deveria ter sido realizada em 2019.

Para completar o rol das investidas conservadoras de forte cariz reacionário, foi lançado, em 2019, o Programa Pátria Voluntária, que tem como presidente a primeira-dama do país, Michele Bolsonaro e se assenta nas chamadas parcerias público-privadas. Em uma única tacada o governo renova práticas que remota a pior cultura histórica do campo da assistência social: o primeiro-damismo e o voluntariado.

O processo de desmonte da já frágil estrutura do SUAS segue curso, intensificando o desfinanciamento. De acordo com o Conselho Nacional de Assistência Social (CNAS), em 2019, o valor orçamentário aprovado por Resolução do CNAS foi de R\$ 2.739.858 bilhões, enquanto que o que foi efetivamente autorizado pelo governo federal foi R\$ 1,6 bilhão. Para 2020, o orçamento previsto pela LOA, para o Fundo Nacional de Assistência Social (FNAS), R\$ 1,34 bilhão, é pelo menos $15 \%$ menor que o valor aprovado no ano passado.

A Portaria no 2362 do Ministério da Cidadania (publicada em 20 de dezembro de 2019) tem efeito destruidor sobre o SUAS e praticamente inviabiliza a manutenção de serviços em muitos municípios, principalmente os de porte 1 , haja vista a profunda dependência do cofinanciamento federal. Visa promover a equalização dos repasses realizados pelo FNAS aos Fundos de Assistência Social municipais, estaduais e distrital, priorizando o repasse de recursos limitados ao exercício financeiro vigente, conforme a disponibilidade financeira.

De acordo com Nota do Congemas (2020), as implicações são graves sobre o SUAS, principalmente, em função de efeitos de "não pagamento de Despesas de Exercícios Anteriores; pelo repasse condicionado à célere execução dos recursos, desconsiderando-se os ritmos e processos inerentes ao ciclo da política nas demais esferas de governo" (CONGEMAS, 2020, p. 2). A portaria implica ainda no não pagamento de dívidas relativas a exercícios orçamentários anteriores (2017-2019) e, para o exercício de 2020, a redução de repasse de parcelas do cofinanciamento para alguns municípios chega a $40 \%$. 
Mesmo para o Bolsa Família, que tem séries históricas de crescimento orçamentário, há previsão de corte de $\mathrm{R} \$ 3$ bilhões. $A$ PLOA previa o atendimento de 13,2 milhões de famílias, uma redução de 400 mil famílias em relação a 2019. De acordo Neri (2020),em termos líquidos, cerca de 1,1 milhões de famílias foram desligadas do programa entre maio de 2019 e janeiro de 2020. Segundo Paiva (et al, 2020), o PBF possui uma fila estimada de aproximadamente 1,7 milhão de famílias.

\section{A Política de Assistência Social no contexto da pandemia do Novo Coronavírus}

Parece muito improvável que o SUAS possa manter a continuidade de serviços e atendimentos, afiançando provisões de segurança e acolhimento, assegurando condições de saúde dos seus trabalhadores e dos usuários face os riscos de contaminação do Novo Corona Vírus, considerando as já conhecidas fragilidades da rede de serviços socioassistenciais. Ademais, os ataques recentes à sua institucionalidade, o desfinanciamento contínuo, ao mesmo tempo em que já vinham sendo insufladas as demandas sobre a política de assistência social, em função do aumento da pobreza, do desemprego, do trabaIho precário e das perdas de direitos trabalhistas e da proteção social atinentes ao emprego, agudizam os problemas. Se acoplarmos a este cenário, o agravamento exponencial que a pandemia cria sobre as condições de vida das camadas mais empobrecidas e precarizadas dos trabalhadores, parece muito provável que também o SUAS possa colapsar.

Bastou a crise sanitária fazer vir à tona, sem possibilidades de camuflagem, às mais profundas mazelas do capitalismo dependente brasileiro, expondo o contingente de trabalhadores em trabalho informal e sem garantias trabalhistas, a pobreza absoluta de pessoas que sobrevivem através das atividades mais precárias, instáveis e espoliativas, a fragilidade de rendimentos de indivíduos que sobrevivem da autoexploração intensiva e de seus familiares, glamourizados sob o mantra do empreendedorismo, terceirizados, artistas, pequenos comerciantes, vendedores ambulantes, trabalhadoras domésti- 
cas, trabalhadores de aplicativos de toda sorte e uma miríade de tantos outros que compõem o fenômeno da uberização do trabalho.

A Pandemia desvela a própria barbarização da vida que o capitalismo opera na tentativa de garantir sua reprodução ampliada, mas como afeta - ainda que não da mesma forma - setores médios e altos da burguesia - a crise sanitária requer do Estado e da sociedade medidas que possam mitigar os estragos mais nefastos. A política de assistência social que vem, no Brasil, assumido funcionalidade nos últimos anos para dar conta de demandas da reprodução da classe trabalhadora, sobretudo sua fração mais empobrecida ou, para usar termos do Marx, aquele contingente que compõe a superpopulação relativa estagnada (MARX, 2013), é requisitada a intensificar suas ações.

Neste sentido, a "correria" estatal para garantir medidas de contingenciamento da pandemia passa a tentar "remediar" em dias, o estrago dos últimos 4 anos, permitindo, por exemplo, o uso de saldos de contas dos Fundos municipais de assistência social e flexibilizando a alocação dos recursos para facilitar compra de suprimentos e Equipamentos de Proteção Individual (EPIs) (Portaria Conjunta № 1 /2020,Ministério da Cidadania). Nessa mesma linha, a Secretaria Nacional de Assistência Social (SNAS) informou ${ }^{2}$ que foi designado um Crédito Extraordinário - Enfrentamento do Coronavírus, no valor de R\$2,550 bilhões sob Medida Provisória № 953, de 2020. ${ }^{3}$

De acordo SNAS, o recurso poderá ser aplicado tanto na PSB como na PSE, podendo ser usado na contratação de pessoal, no pagamento de alimentação complementar de usuários e equipes, pagamentos de serviços de terceiros, incremento aos benefícios eventuais, como contratos funerários, (sic), contratação de cuidadores, gasto com custeio, comprar EPIs, contratação de serviço de comunicação, melhorar e adequar infraestrutura para garantias de segurança quanto ao contágio, equipamentos de ventilação, eletrônicos, ampliação ou instalação de rede de internet etc. A prioridade inicial será para melhorias nas unidades de acolhimento, públicas ou da rede conveniada, dando ênfase às situações decorrentes da população em

${ }^{2}$ Em live no Canal da Conferência Nacional de Municípios, no youtube no dia 17/04/2020. Disponivel em: <https://www.youtube.com/watch?v=g9V4sE YwhE >.

${ }^{3}$ Até a finalização desse texto a MP ainda estava em tramitação. 
situação de rua. A transferência de início se dará mediante ranqueamento, em função da quantidade de pessoas em situação de rua nos municípios.

Em suma, o crédito especial procura "tapar buracos". Não que o SUAS possa dispensar esse recurso. Entre a vida e a morte de miIhões de pessoas, é preciso fazer o que for possível. O que evidenciamos é que políticas protetivas não se estruturam do dia para noite e que paliativos não resolvem as fragilidades que o SUAS vem carregando. A autorização para uso do crédito provisório nos itens elencados, com exceção do incremento ao auxílio funerário - que sinaliza para a tragédia humana da pandemia - são todos eles demandados pelos serviços socioassistenciais desde sempre.

A contratação de pessoal temporário é urgente e acentuada pelo novo contexto, mas as equipes de referência sempre foram defasadas e cada vez mais reduzidas no último ano. A ausência de concurso público, as contratações temporárias e precarizadas dos trabaIhadores implicam em alta rotatividade profissional, o que inviabiliza continuidade de projetos e ações, bem como limita o conhecimento da abrangência territorial e suas particularidades.

Enquanto as tramitações correm na esfera federal, o solo concreto onde o SUAS acontece, isto é, os municípios, segue em atropelos, arranjos e desespero das equipes e, por vezes, desmandos das gestões locais. Fóruns Estaduais de Trabalhadores do SUAS, como o FETSUAS-RJ, fazem denúncias sobre as condições de trabalho dos profissionais que estão na linha de frente para gerir "o caos" e manter serviços e atendimentos, sem plano de contingências, protocolos de atendimentos ou informações sobre uso de EPIs, quando há. Filas nos CRAS com demandas por cestas básicas, para viabilização de documentos e dúvidas sobre o auxílio emergencial, ${ }^{4}$ cadastramento no Cadastro Único; situações de violência doméstica infantil e de gênero (intensificadas com o isolamento social); visitas domiciliares; superlotação das unidades de acolhimento, aglomerações nos centros POP,

\footnotetext{
${ }^{4}$ Sobretudo para garantir o acesso ao Auxílio Emergencial aprovado pelo Congresso Nacional, no valor de $\mathrm{R} \$ 600,00$ por trabalhador, podendo abranger até duas pessoas por domicílio, desde que não recebam nenhum benefício assistencial ou previdenciário, exceto Bolsa Família. Nos limites deste breve texto não é possível problematizar as questões que atravessam a aprovação e garantia de recebimento do auxílio pelos trabalhadores.
} 
condições insalubres nos abrigamentos provisórios, falta de regulamentação dos Benefícios Eventuais - o que não é mero descaso dos municípios, mas a possibilidade de uso clientelista dessa modalidade de benefício.

A abertura de crédito extraordinário não é apenas insuficiente para as demandas em função do enfrentamento à Pandemia, como não significa recomposição do orçamento da política de assistência social. Ainda mais grave é o fato de que "o orçamento ordinário para assistência social não está sendo executado e não existe previsão de que seja restituído", conforme aponta o Estudo da "Coalizão Direitos Valem Mais" (2020).

Por exemplo: a ação orçamentária 219E, referente a ações de proteção social básica, teve orçamento autorizado de $\mathrm{R} \$ 1$ biIhão para 2020; entretanto, até setembro deste ano apenas $\mathrm{R} \$$ 188 milhões foram empenhados. Na ação $219 \mathrm{~F}$, de ações de proteção social especial, do orçamento autorizado de $\mathrm{R} \$ 515$ milhões, apenas $\mathrm{R} \$ 105$ milhões foram empenhados, conforme dados dos SIOP (COALIZÃO DIREITOS VALEM MAIS, 2020, p. 11).

Desde 2014 a Função 08, do Orçamento da Seguridade Social, vem perdendo recursos, conforme indicamos. Para ratificar, vale indicar, mais uma vez, o Estudo da "Coalizão Direitos Valem Mais (2020), que demonstra que entre 2014 e 2020 o Orçamento Inicial para a Assistência Social caiu de $\mathrm{R} \$ 3$ bilhões para $\mathrm{R} \$ 1,3$ bilhão, uma redução de $57 \%$. Esse quadro tende a piorar com as projeções da PLOA de 2021.

Para retomar o patamar de 2014, o valor de $\mathrm{R} \$ 2,72$ bilhões corrigido pelo IGP-M (FGV) de dez/2014 a agosto/2020, estaria em $\mathrm{R} \$ 4,08$ bilhões. Isso representa um percentual baixo no montante de R\$ 102 bilhões previstos no PLOA 2021, de exatos $4 \%$ do total proposto para as despesas na Função 08 . Um critério a ser utilizado, mais próximo das despesas empenhadas pelos municípios, Distrito Federal e estados, é a recomposição da inflação. Pelo IGPM - Índice Geral de Preços, tendo como parâmetro os $R \$ 3,7$ bilhões em dezembro de 2013 , é possível che- 
gar ao valor de $\mathrm{R} \$ 5,755$ bilhões, conforme a inflação de 55,56\% (COALIZÃO DIREITOS VALEM MAIS, 2020, p.15).

A Emenda Constitucional 95, favorecida pelo endurecimento da política neoliberal do governo Bolsonaro vem provocando um desastre para o campo das políticas e dos direitos sociais. A ajuste fiscal permanente do Estado brasileiro aponta para um cenário obscuro em torno de uma política social de institucionalidade tão recente, como a política de assistência social. A tragédia é ainda maior, considerandose o aumento do desemprego e da precarização que já estava em curso, no contexto da crise capitalista, e que se tornaram ainda mais potenciais com a crise sanitária.

\section{Considerações finais}

A reflexão que foi apresentada intentou apontar a necessidade de desvelar as causas reais da crise em tela, para não caírem explicações fenomênicas que localizam na própria crise sanitária, provocada pela Covid-19 e nos efeitos da paralisação econômica, o cerne da recessão econômica em andamento. A pandemia concorre para acentuar as dificuldades de valorização do capital, uma vez que medidas de contingenciamento demandaram paralisação da produção de mercadorias e serviços. No entanto, o que vivenciamos é uma crise capitalista, que abarca a totalidade da produção e reprodução desta sociabilidade desde suas determinações mais essenciais - produção e realização do valor - às dimensões sobredeterminadas - aprofundamento da pobreza, precarização do trabalho, desemprego e a própria experimentação da pandemia que é diferenciada em função dos diferentes lugares que os sujeitos ocupam nas relações de produção.

Neste contexto, situamos a política de assistência social e o processo de desmonte de que vem sendo objeto desde 2015. Sua inserção no âmbito dos serviços essenciais a serem mantidos durante as medidas de isolamento social explicitam os sérios problemas de desfinanciamento e os gargalos que o SUAS enfrenta para dar conta das demandas sociais exponenciadas em função da crise sanitária, demonstrando as contradições capitalistas em face da crise. 
No Brasil, o Governo Federal insistiu ferreamente na tese de que o chamado isolamento vertical seria suficiente para conter a propagação da doença, sem causar tantos prejuízos à economia, aprofundando o obscurantismo e o irracionalismo com a defesa infundada e irresponsável do uso do fármaco chamado cloroquina como forma efetiva de tratamento, mesmo quando vários estudos demonstram o contrário.

Assistimos a explosão de infecções e mortes, sem que o Governo apresentasse um Plano efetivo de contingência e enfrentamento à crise sanitária e os efeitos deletérios sobre as condições de emprego, saúde e vida de milhões de trabalhadoras e trabalhadores. Apresenta um insípido gasto efetivo com a política de saúde e não articula formas de atuação conjunta com os Governos estaduais. O país tem estado praticamente "à deriva", com duas trocas ministeriais na Saúde e um ocaso neste ministério sobre a mal chamada "atuação interina" de um general à sua frente. Até 10 de setembro de 2020 o Brasil registrou mais de cinco milhões de casos e mais de 150 mil mortes, com uma inequívoca subnotificação.

Por outro lado, o desemprego acentuado mais a informalidade e a impossibilidade de trabalhar tem acometido frações significativas da classe trabalhadora e insufla demandas sobre o SUAS. Fazemos as críticas necessárias à política de assistência social brasileira e procuramos explicitar suas contradições, que são insuperáveis no marco do capitalismo. Mas também defendemos, junto aos seus trabalhadores e usuários, o quão fundamental é esta política para garantia da sobrevivência de vários segmentos dos trabalhadores neste país. Sempre dissemos que ela é um serviço essencial, ainda que não possa erradicar a desigualdade social. E, padece do sucateamento resultante dos ataques ultraneoliberais, única forma possível para o desenvolvimento capitalista na atualidade, que não comporta sistemas protetivos públicos e expõe os trabalhadores a níveis cada vez mais bárbaros de exploração. Essa mesma lógica de acumulação que destrói recursos naturais e avança sobre ecossistemas, produzindo doenças e contribuindo para disseminação de vírus cada vez mais nocivos, como o Novo Corona Vírus. A política de assistência social que defendemos prioriza a vida e as necessidades humanas. Ela será funda- 
mental durante a Pandemia, mas precisa ser fortalecida agora e depois dela, com investimento massivo público, com a valorização dos trabalhadores e com respeito às suas instâncias de controle social.

\section{Referências}

ANTUNES, Ricardo. O privilégio da servidão: o novo proletariado de serviços na era digital. São Paulo: Boitempo, 2018.

BEHRING, Elaine. Fundo Público, exploração e expropriações no capitalismo em crise. In: Expropriação e Direitos no capitalismo. BOSCHETTI, I. (ORG). São Paulo: Cortez, 2018.

. Notas para um Balanço Crítico do SUAS: a título de Prefácio. In: Revista Em Foco № 05. Conselho Federal de Serviço Social. Rio de Janeiro: 2009.Conselho Nacional de Assistência Social (CNAS), em 2019.

BOTELHO, Maurílio Lima. Epidemia econômica: Covid-19 e a crise capitalista. In: Blog da Boitempo. Disponível em: <https://blogdaboitempo.com.br/2020/04/02/epidemia-economica-covid-19-e-a-crisecapitalista/>. Acesso em: 26 set. 2020.

BRASIL. Decreto no 10.282/2020. Regulamenta a Lei no 13.979, de 6 de fevereiro de 2020, para definir os serviços públicos e as atividades essenciais.

CHESNAIS, François. O estado da economia mundial às vésperas da pandemia. In: Portal Carta Maior. Disponível em: <https://www.cartamaior.com.br/?/Editoria/Economia-Politica/O-estado-da-economia-mundial-as-vesperas-da-pandemia/7/47164>. Acesso em: 10 set. 2020.

COALIZÂO DIREITOS VALEM MAIS. Nota Técnica LDO/LOA 2021 E PEC 188. Disponível em: <https://direitosvalemmais.org.br/2020/09/30/ nota-tecnica-Idoloa-2021-e-pec-188-piso-minimo-emergencial-paraservicos-essenciais-desmonte-do-estado-pela-pec-do-pacto-federativo-e-necessidade-de-mudancas-urgentes-nas-regras-fiscais/>. Acesso em: 03 out. 2020. 
COLEGIADO NACIONAL DE GESTORES MUNICIPAIS DE ASSISTÊNCIA SOCIAL - CONGEMAS. Posicionamento do CONGEMAS acerca da Portaria no 2.362 de 20 de dezembro de 2019 do Ministério da Cidadania.

COLETIVO CEM FLORES. A Pandemia, a Recessão, as Medidas Burguesas e a Reação dos Trabalhadores no Mundo e no Brasil. Disponível em: <https://cemflores.org/index.php/2020/03/20/a-pandemiaa-recessao-as-medidas-burguesas-e-a-reacao-dos-trabalhadores-nomundo-e-no-brasil/>. Acesso em: 24 set. 2020.

DILIGENTE, Marcos Pereira; ARAúJO, Ricardo Souza. Nova Previdência: o austericídio neoliberal sob a ótica dateoria marxista da dependência. In: Revista Textos \& Contextos (Porto Alegre), v. 18, n. 1, p. 67-77, jan./jun. 2019.

FÓRUM ESTADUAL DE TRABALHADORES DO SUAS/RJ (FETSUAS/RJ). Nota do FETSUAS-RJ sobre o trabalho na política de assistência social e a pandemia do COVID-19. Rio de Janeiro, 2020.

HARVEY, David. Política anticapitalista na época do COVID-19. Disponível em: <https://blogdaboitempo.com.br/2020/03/24/david-harvey-politica-anticapitalista-em-tempos-de-coronavirus/>. Acesso em: 03 maio 2020.

IAMAMOTO, Marilda Vilela. Serviço Social em Tempo de Capital Fetiche: capital financeiro, trabalho e questão social. São Paulo: Cortez,2008.

NERI, Marcelo. FGV Social comenta os cortes no Bolsa Família e o aumento da extrema pobreza no Brasil. Disponível em: <https:// cps.fgv.br/destaques/fgv-social-comenta-os-cortes-no-bolsa-familiae-o-aumento-da-extrema-pobreza-no-brasil>. Acesso em: 28 mar. 2020.

MARX, Karl. O capital - Livro 1. São Paulo: Boitempo, 2013

MENDES, Áquilas.; CARNUT, Leonardo. Lucro ou vidas? Coronavírus e o voto de Minerva. In: Revista Movimento. Disponível em:

$<$ https://movimentorevista.com.br/2020/04/lucro-ou-vidas-coronavirus-e-o-voto-de-minerva/>. Acesso em: 19 abr. 2020. 
MINISTÉRIO DA CIDADANIA. Portaria Conjunta № 1/2020. Dispõe acerca da Utilização de recursos do Cofinanciamento Federal no atendimento às demandas emergenciais de enfrentamento ao Coronavírus (Covid-19) no âmbito do Sistema Único de Assistência Social.

. Portaria no 2362/2019. Dispõe sobre acompanhamento do cofinanciamento do SUAS.

MOTA, Ana Elizabete. A centralidade da assistência social na Seguridade Social brasileira nos anos 2000. In: 0 mito da assistência social: ensaios sobre Estado, Política e Sociedade. MOTA, Ana Elizabete (Org.). 2. ed. São Paulo: Cortez, 2008.

PAIVA, Luiz Henrique.; SOUZA, Pedro. H. G. Ferreira de Souza; BARTHOLO, Letícia.; SOARES, Sergei. Evitando a Pandemia da pobreza: possibilidades para o Programa Bolsa Família e Para O Cadastro Único em resposta à Covid-19. In: Nota Técnica/IPEA. 2020.

PEIXOTO, Elza Margarida de Mendonça. Et al. CRISE DO CAPITAL, CRISE SANITÁRIA, CRISE POLÍTICA. In: Revista Germinal: Marxismo e Educação em Debate, Salvador, v. 11, n. 3, p. 30-73, dez. 2019..

RODRIGUES, V. A. ; STAMPA, I. A pandemia e a 'inteligência' do presidente. In: ANA LOLE; INEZ STAMPA; RODRIGO LIMA R. GOMES [ORGS.]. Para além da Quarentena: reflexões sobre crise e pandemia. Rio de Janeiro: Mórula Editorial, 2020.

SILVA, Mossicleia Mendes. Desenvolvimento capitalista e assistência social no Brasil: a encruzilhada da modernização com o Plano Brasil sem Miséria, 2011-2016. 2018. Tese de Doutorado. Programa de Pósgraduação em Serviço Social /Universidade do Estado do Rio de Janeiro, 2018.

\section{Sobre a autora}

Mossicleia Mendes da Silva - Professora Adjunta na Escola de Serviço Social da Universidade Federal do Rio de Janeiro. Pesquisadora no Laboratório de Pesquisa GEMPS - Grupo de Estudos e Pesquisas Marxistas em Política Social -NEPEM/UFRJ. Estudos e pesquisas voltados 
para o campo da política de assistência social e as particularidades do Estado social no capitalismo dependente brasileiro no trato as demandas da reprodução da força de trabalho; Membro do Comitê de Iniciação Científica e Tecnológica da UFRJ.

E-mail: mossi_c@yahoo.com.br 